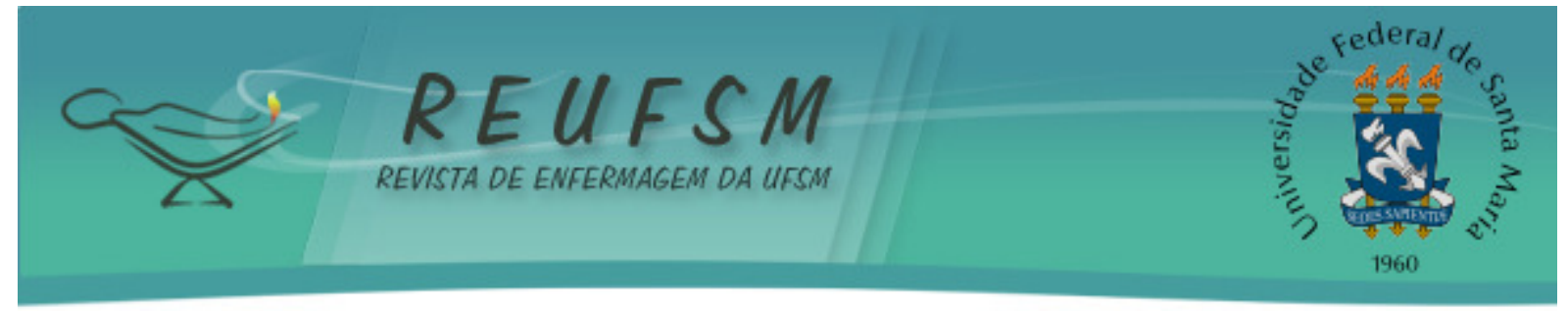

ARTIGO ORIGINAL

\title{
ESTRESSE OCUPACIONAL EM ENFERMEIROS ATUANTES EM SETORES FECHADOS DE UM HOSPITAL DE PELOTAS/RS
}

\author{
OCCUPATIONAL STRESS IN NURSES ACTING IN CLOSED UNITSOF A HOSPITAL IN \\ PELOTASIRS
}

\section{ESTRÉS LABORAL EN ENFERMEROS QUE TRABAJAN EN SECTORES CERRADOS DE UN HOSPITAL DE PELOTASI RS}

\author{
Michele Cristiene Nachtigall Barboza ${ }^{1}$ \\ Luciana Lima Braga² \\ Luiane Tietz Perleberg ${ }^{3}$ \\ Lidiane Souza Bernardes ${ }^{4}$ \\ Izabella Chrystina Rocha ${ }^{5}$
}

Doi: $10.5902 / 217976927624$

RESUMO: Objetivo: descrever os fatores estressantes na atividade do enfermeiro que trabalha nos setores fechados de instituição hospitalar. Método: trata-se de um estudo descritivo com enfoque qualitativo, desenvolvido com sete enfermeiras que trabalham na Unidade de Terapia Intensiva e no Bloco Cirúrgico. Os dados foram coletados nos meses de julho e agosto de 2011, mediante entrevista semiestruturada e após assinatura do termo de consentimento Livre e Esclarecido, utilizando análise temática como ferramenta de interpretações. Resultados: Foram encontrados os seguintes eixos temáticos: estrutura física e recursos materiais; relacionamento interpessoal; e gerenciamento como causa de estresse. Considerações Finais: a atuação do enfermeiro encontra-se relacionada ao cuidado humano, sendo esta permeada por atividades burocráticas e assistenciais, as quais podem enfrentar situações complicadas de convívio, questões éticas, valores e crenças.

Descritores: Enfermagem; Esgotamento profissional; Unidades de terapia intensiva; Enfermagem perioperatória.

ABSTRACT: Aim: To describe the stressors in the activity of nurses working in the hospital closed units. Method: This is a descriptive study with qualitative approach, developed with seven nurses working in the Intensive Care Unit and the Surgical Block. Data were collected in July and August 2011, by semi-structured interview and after signing the free and informed consent, using thematic analysis as a tool for interpretation. Results: We found the following themes: physical structure and material resources, interpersonal, and management as a cause of stress. Final Thoughts: The nurse's role is related to human care, which are permeated by bureaucratic activity and care, which may face tricky situations convivial question ethics, values and beliefs.

Descriptors: Nursing; Burnout, professional; Intensive care units; Perioperative nursing.

RESUMEM: Objetivo: Describir los factores de estrés en la actividad del enfermero que trabaja en los sectores cerrados de un hospital. Método: Se trata de un estudio descriptivo

\footnotetext{
${ }^{1}$ Enfermeira. Mestre em Enfermagem pela FURG. Professora Assistente do Curso de Enfermagem da Universidade Federal de Pelotas. Pelotas, RS, Brasil. Email: michelenachtigall@yahoo.com.br

${ }^{2}$ Enfermeira. Faculdade Anhanguera de Pelotas. Pelotas, RS, Brasil. Email: lulimabraga@hotmail.com

${ }^{3}$ Enfermeira. Faculdade Anhanguera de Pelotas. Pelotas, RS, Brasil. Email: luiane_@hotmail.com

${ }^{4}$ Enfermeira. Universidade Federal de Mato Grosso. Email: Lidiane.bernardes@hotmail.com

${ }^{5}$ Enfermeira. Mestre em Enfermagem. Professora Assistente do Curso de Enfermagem da Universidade Federal de Mato Grosso. Email: izabella.bebel@hotmail.com
} 


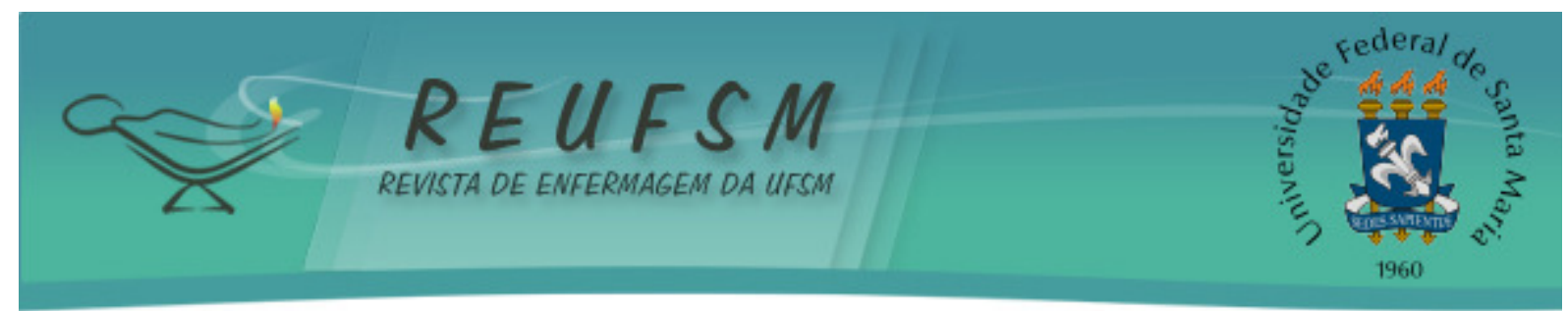

con enfoque cualitativo, desarrollado con siete enfermeras que actúan en la Unidad de Cuidados Intensivos y en el Bloque Quirúrgico. Los datos fueron recolectados en julio y agosto de 2011, mediante entrevista semiestructurada y después de firmar el consentimiento Libre y Esclarecido, mediante el análisis temático como herramienta para la interpretación. Resultados: Se encontraron los siguientes temas: la estructura física y recursos materiales, relacionamiento interpersonal y de gerenciamiento como una causa de estrés. Consideraciones finales: El papel del enfermero se encuentra relacionado con el cuidado humano, siendo estas permeadas por actividades burocráticas y asistenciales, que pueden enfrentar situaciones difíciles de convivencia, cuestiones éticas, valores y creencias. Descriptores: Enfermería; Agotamiento profesional; Unidades de cuidados intensivos; Enfermeríaperioperatoria.

\section{INTRODUÇÃO}

O estresse é conceituado como um esforço de adaptação do organismo para enfrentar situações que considere ameaçadoras à sua vida e ao seu equilíbrio interno, sendo uma reação fisiológica natural de sobrevivência. ${ }^{1}$ Pode ser definido como um conflito de personalidade ou um conflito inconsciente específico que possibilita o desenvolvimento de um transtorno mental. ${ }^{2}$ Atualmente, o estresse significa pressão, como ter muito trabalho e/ou problemas, ou estar sob a ação de um determinado estímulo insistente. ${ }^{3}$

Ao relacionar o estudo sobre estresse à enfermagem, observa-se uma equipe composta por profissionais qualificados, engajados na promoção, prevenção, proteção e recuperação da saúde no âmbito individual e coletivo, o que nem sempre significa satisfação plena com o trabalho. Inserido nesse contexto está o enfermeiro, coordenador da equipe, o qual exerce sua atividade com habilidades técnicas, humanistas, reflexivas e generalistas. Entretanto, devido a uma sobrecarga de funções, responsabilidades por condutas e atitudes referentes à sua equipe, as atividades do enfermeiro podem ser consideradas estressantes. ${ }^{4}$ Isso porque, em sua dinâmica laboral, os enfermeiros estão expostos a diversos estímulos físicos e mentais que os tornam mais suscetíveis a desenvolver os sintomas de estresse. ${ }^{5}$

$\mathrm{Na}$ perspectiva do estudo sobre o estresse em profissionais de enfermagem dentro de uma área fechada, identificam-se dois setores: o bloco cirúrgico $(\mathrm{BC})$ e a unidade de terapia intensiva (UTI), os quais têm o estresse como uma das características, devido à convivência mais intensa e conflituosa dos diversos profissionais de saúde que lidam com a instabilidade clínica dos pacientes atendidos nesses setores. ${ }^{6}$

Nesse sentido, são considerados setores fechados aqueles localizados em áreas isoladas do hospital, onde exista pouca circulação de pessoas, com a finalidade de minimizar a incidência de infecções hospitalares. Assim, o acesso a esses setores é restrito ao paciente e aos profissionais que neles atuam, como é o caso do Bloco Cirúrgico e a Unidade de Terapia Intensiva. ${ }^{7}$

É possível identificar esses setores, extremamente importantes de uma instituição hospitalar, como causadores de estresse. Esse esforço que o organismo tende a desenvolver, em relação ao profissional de enfermagem, é decorrente do barulho causado pelos equipamentos, dos sons produzidos em excesso pelas equipes de saúde, da iluminação inadequada, da ventilação imprópria, da falta de material ou da tecnologia obsoleta para realizar as atividades. Enfim, as inadequações do ambiente hospitalar em que atuam acabam levando o profissional à irritação e ao cansaço, prejudicando sua saúde e, por consequência, a qualidade na assistência ao paciente. ${ }^{6}$

Além disso, o relacionamento interpessoal é outro fator determinante para a geração de estresse, pois a falta de um bom convívio entre as equipes de trabalho pode afetar 


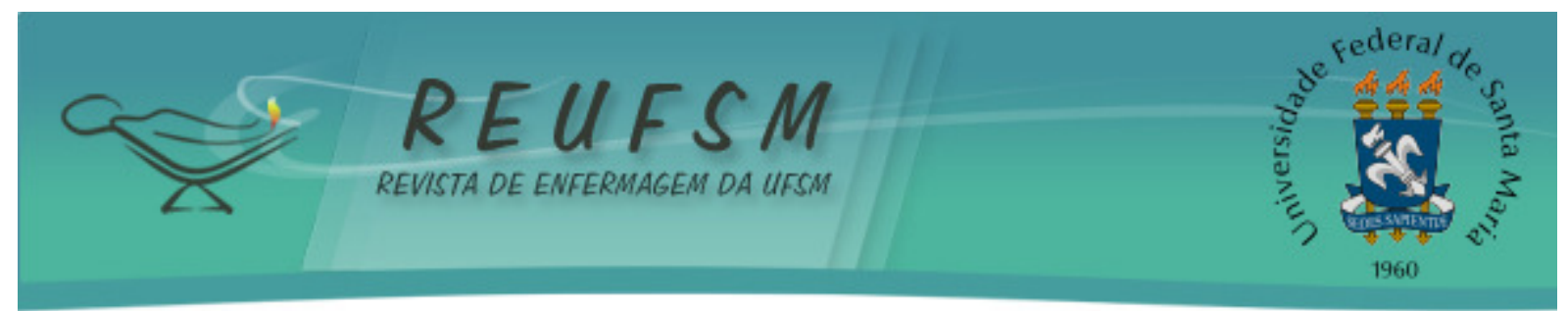

diretamente o atendimento prestado ao paciente e a satisfação pelo serviço desenvolvido no trabalho. 0 individualismo, a carência na cooperação do trabalho em equipe, o déficit de recursos humanos, a rapidez no atendimento e a não finalização dos cuidados com o paciente podem causar uma sobrecarga de trabalho e consequentemente o estresse. ${ }^{6}$

Ao considerar o crescimento elevado do estresse na área de saúde, em especial da enfermagem, vê-se como necessidade a elaboração de medidas preventivas, na perspectiva de minimizar essa problemática. Para isso, é importante salientar as condições de trabalho dos enfermeiros em setores fechados, uma vez que o estresse gerado pelo trabalho pode permitir o desenvolvimento de sentimentos de angustia e frustração, podendo assim interferir na qualidade de vida do profissional e do serviço oferecido.

Diante dessas constatações formulou-se a seguinte questão norteadora: Quais os fatores estressantes na atividade do enfermeiro que trabalha em setores fechados de uma instituição hospitalar?

Desta forma, este estudo teve como objetivo descrever os fatores estressantes na atividade do enfermeiro que trabalha em setores fechados de uma instituição hospitalar.

\section{MÉTODO}

Este estudo tem como característica ser descritivo, exploratório e de caráter qualitativo, sendo realizado a partir da colaboração de enfermeiros dos setores fechados (BC e UTI) de um hospital do sul do Rio Grande do Sul, RS, Brasil. Teve sua coleta desenvolvida no mês de novembro de 2011, mediante um roteiro de entrevista semiestruturada, após a apresentação e a assinatura do Termo de Consentimento Livre e Esclarecido (TCLE).

Fizeram parte desta pesquisa, como sujeitos, os enfermeiros que preencheram critérios de inclusão, como ser enfermeiros atuantes nos seguintes setores fechados: Bloco Cirúrgico e Unidade de Terapia Intensiva nos três turnos de trabalho; a aceitação da gravação da pesquisa e a assinatura do TCLE em duas vias. A partir dessas colocações, foram entrevistados sete enfermeiros das unidades estudadas, sendo eles, cinco enfermeiros da UTI e dois enfermeiros do BC. Por fim, para a realização da pesquisa, foram respeitados os preceitos éticos da Resolução Conselho Nacional de Saúde 196/96, como o anonimato, identificando os sujeitos com nome fictício de flores.

Para possibilitar a realização deste estudo, a pesquisa foi submetida ao Comitê de Ética e Pesquisa para sua aprovação, conforme protocolo $n^{\circ} 172 / 2011$ - ata100, bem como pela Comissão de Ética do Hospital onde foi desenvolvida.

A análise dos dados foi realizada por meio da análise temática. Desse modo, foram adotados os seguintes passos: primeiramente foi feita uma pré-análise, realizada a partir da transcrição das gravações, organização dos relatos, leitura e releitura do material coletado, a fim de retomar o objetivo da pesquisa. Posteriormente, foi realizada a exploração do material, que consiste na operação classificatória que visa alcançar o núcleo ou a unidade de compreensão do texto, com a intenção de encontrar as categorias que são expressões ou palavras significativas de uma fala que será organizada em categorias ou temas. ${ }^{9}$

\section{RESULTADOS E DISCUSSÃO}

Neste estudo, todos os entrevistados são do sexo feminino e suas faixas etárias encontram-se entre 26 e 44 anos. Quanto ao tempo de formação, apresentam de 03 a 07 anos e de atuação na instituição de 04 meses a 06 anos. A maioria dos entrevistados trabalha seis horas por dia, com turnos alterados entre manhã, tarde e noite, sendo que na maior parte trabalha somente na instituição pesquisada. 


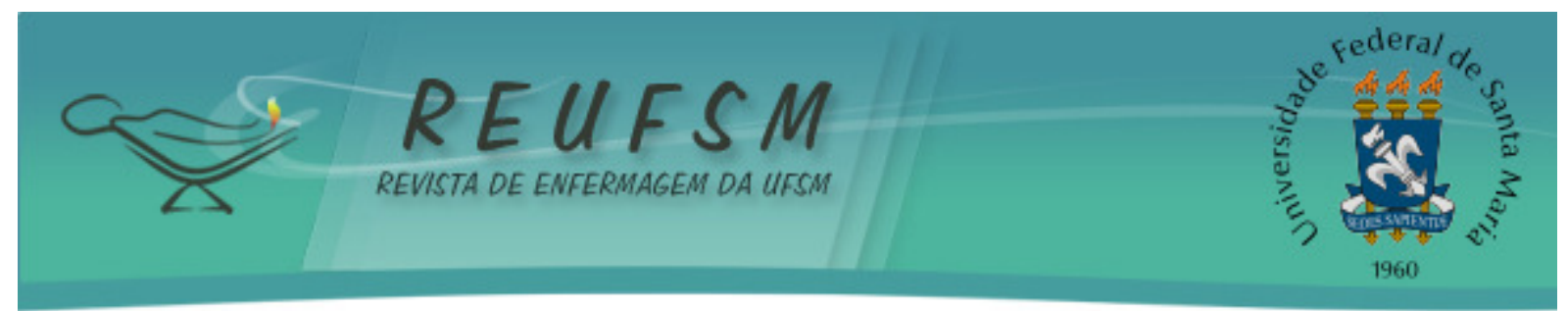

A análise dos dados permitiu, conduziu e construiu três eixos temáticos: a estrutura física inadequada e a falta de recursos materiais como fator estressante; as relações interpessoais geradoras de estresse no ambiente de trabalho; o estresse do enfermeiro no gerenciamento/administração do ambiente fechado.

\section{A estrutura física inadequada e a falta de recursos materiais como fator estressante}

A estrutura física e os recursos materiais são instrumentos básicos e indispensáveis para o desenvolvimento do cuidado de enfermagem. Nesse sentido, as inadequações de recursos físicos e materiais enfatizam-se nessa conjuntura como fatores estressantes.

[...] Falta respirador [...] são 05 respiradores para 10 leitos, alguém vai ter que ambuzar a noite toda (risos) [...] às vezes não tem lençol e falta medicação. (Girassol)

[...] A estrutura física antiga... aqueles aparelhos têm cinquenta anos e agora estragam toda semana, além da precariedade dos nossos instrumentos e materiais. (Rosa)

[...] Nós temos dois elevadores antigos, quando estraga a dificuldade é maior ainda. (Orquídea)

[...] Equipamentos que não funcionam [...] a gente não tem uma central de esterilização. (Violeta)

[...] Tu precisa da medicação no carro de parada, aí tu vai ver lá e não tem. (Margarida)

Pode-se observar que os problemas na estrutura física da instituição, como um elevador antigo e que estraga com frequência, podem ser considerados fatores desencadeadores de estresse. Além disso, uma central de esterilização é importante e necessária para setores como BC e UTI, somados aos recursos materiais precários gerando estresse na equipe estudada.

Estresse ocupacional é definido sob uma perspectiva transacional, em que existe uma interação entre o indivíduo e a situação estressante. ${ }^{10}$ É evidenciado como um estado emocional desagradável, pela tensão, frustração, ansiedade, exaustão emocional em função de aspectos do trabalho definidos pelos indivíduos como ameaçadores. ${ }^{11}$

A falta de uma central de material e esterilização dificulta o processo de trabalho, causando o estresse ocupacional nos profissionais da saúde. Essa área é uma unidade que se articula com todos os setores do hospital, fornecendo os produtos médicos. Sendo assim, interfere diretamente na qualidade da assistência prestada, preocupação esta dos enfermeiros, pois sem esses materiais esterilizados não seria possível garantir o cuidado à clientela. ${ }^{12}$

Ademais, o planejamento de uma estrutura física hospitalar traz um melhor aproveitamento dos espaços, melhora a organização e as condições de trabalho, fornecendo um ambiente seguro para o cliente e para o profissional. ${ }^{13}$ Isso significa que a escassez de recursos físicos e materiais implica em uma qualidade de atendimento diminuída e demanda um maior esforço físico e psíquico nos trabalhadores, podendo induzir ao estresse. ${ }^{14}$

Por conseguinte, os recursos materiais e físicos são instrumentos básicos e indispensáveis para o desenvolvimento de um cuidado mais complexo de enfermagem. Além disso, acelera o processo de diagnóstico e tratamento, mantendo a integridade física do cliente e do profissional. ${ }^{15}$ 


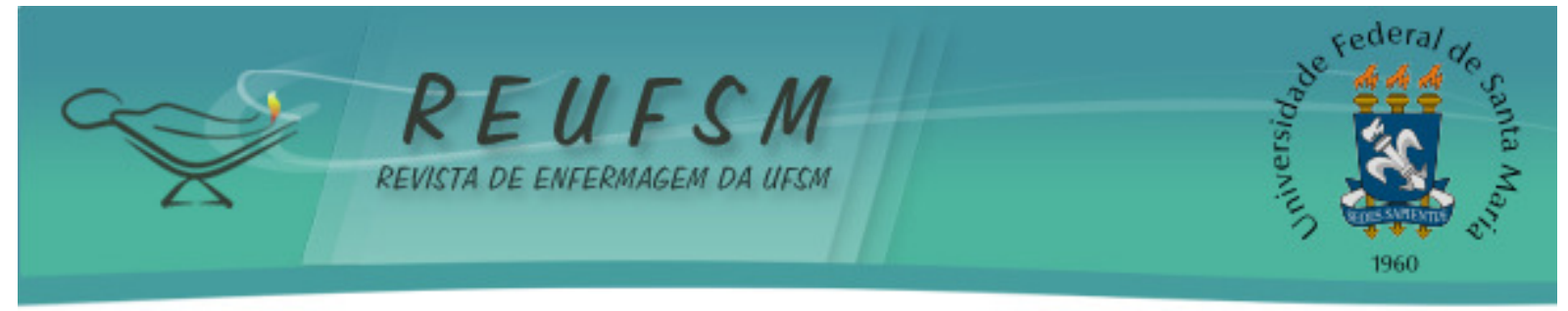

As relações interpessoais geradoras de estresse no ambiente de trabalho

As relações interpessoais no ambiente de trabalho são reconhecidas pelos sujeitos como geradoras de estresse, sendo ainda destacadas a falta de respeito, vínculos de amizade, postura ética e compreensão.

[...] Existe, sim, às vezes meus funcionários parecem crianças, eles brigam entre eles, aí ficam de piadinha e eu tenho que estar sempre apaziguando. (Girassol)

[...] A gente tem que estar sempre lembrando a postura ética, já que existe estresse, [...] normalmente a gente tenta manter $o$ ambiente mais harmonioso possível, pois ele já é fechado, mas para isso é importante estar atento para resolver da melhor maneira possivel os problemas entre a equipe de enfermagem. (Margarida)

[...] Com certeza tem estresse na equipe de enfermagem, a gente não vai ter afinidade com todo mundo. (Tulipa)

[...] Os médicos ficam lá te incomodando, eles querem tudo com rapidez, começam a ficar nervosos e aí tremem com a equipe toda. (Orquídea)

[...] O mais estressante é o manejo com familiar, tem familiar que não entende, quer uma solução rápida. (Lírio)

Pode-se observar, diante dos relatos, as relações interpessoais como geradoras de estresse no ambiente de trabalho. As diversidades de comportamento e personalidade singulares suscitam o atrito entre os profissionais, o que compromete as relações. Além disso, existem as dificuldades de relacionamentos com os familiares que, por terem seus entes em um ambiente hospitalar, agem em determinadas circunstâncias com ato de incompreensão, prejudicando a comunicação. Ademais, deve-se destacar também a relação médica com a equipe de enfermagem, evidenciando um trabalho hierárquico e não sistemático. Por isso pode-se salientar que o funcionamento de um setor fechado deve funcionar com uma engrenagem, havendo responsabilidade, compromisso e respeito mútuo.

0 estresse ocupacional pode surgir mediante os problemas de relacionamento entre a equipe de enfermagem e a equipe multidisciplinar, evidenciado pela falta de cooperação, comunicação deficiente e privilégios de alguns integrantes da equipe. ${ }^{16}$ Já as solicitações recebidas por familiares podem ser consideradas como causadora de estresse por exigirem rápida resolutividade no tratamento e na reabilitação da saúde ${ }^{17}$, as quais, inúmeras vezes, independe da assistência do enfermeiro. Porém, esse profissional é um dos mais pressionados no que diz respeito à disponibilidade e atenção ao ouvir.

Entretanto, para que os problemas nas relações humanas sejam minimizados, é necessária uma interação mútua entre o grupo, evitando a individualização, a insegurança e a competitividade. Ainda mais, prevenindo tensões e elevados níveis de estresse para que, dessa forma, se garanta um convívio agradável entre colegas no local de trabalho. Por isso se estabelece a importância de uma boa relação entre o grupo, para proporcionar a saúde individual e profissional. ${ }^{17}$

A atuação do enfermeiro encontra-se relacionada ao cuidado humano. Nessa atividade o profissional pode enfrentar situações complicadas de convívio, questões éticas, 


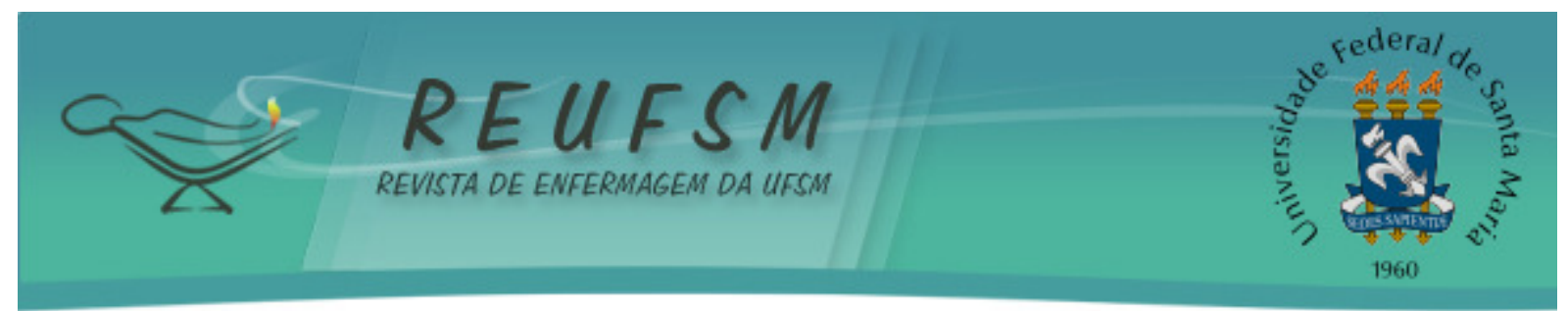

valores ou crenças diversificadas. Diante destes problemas, o enfermeiro deve avaliar a melhor maneira de agir, evitando problemas com colegas, pacientes ou familiares, utilizando seus conhecimentos científicos para resolver tais situações. ${ }^{18}$

0 desenvolvimento de atividades nas equipes de enfermagem geram confronto devido às divergências pelas singularidades de cada trabalhador e pela relutância do cumprimento das tarefas em grupo. ${ }^{16}$ Essas disputas entre os membros do grupo são propícias para a geração de estresse nos indivíduos que trabalham nos setores fechados.

Para evitar desentendimentos que acarretem o estresse, a comunicação de maneira clara torna-se uma ferramenta importante no relacionamento da equipe, permitindo a interação entre as pessoas, a partilha de opiniões e de informações, além da expressão de sentimentos e emoções. ${ }^{19}$ Desta forma, o ato de comunicar será visto como uma estratégia para promover um bom relacionamento entre equipe. Diante disso, os enfermeiros são importantes por estarem incumbidos da tarefa de mediar sua equipe, bem como pelo fato de permanecerem atentos às manifestações de sinais e sintomas sugestivos de estresse no grupo, evitando assim maiores consequências. ${ }^{16}$

Também foram identificadas singularidades de convívio diário nas relações de pacientes e seus familiares com a equipe de enfermagem e médica, o que denuncia 0 estresse causado no ambiente fechado. No presente estudo, todos os enfermeiros relataram situações que podem ocasionar esse transtorno. Sendo assim, acredita-se que os conflitos gerados em torno das equipes de trabalhos, envolvendo ou não pacientes e seus familiares, devem-se ao fato de o grupo atuar em um setor fechado. Nesses ambientes o funcionamento é concentrado e a equipe encontra-se mantida constantemente dentro do setor, ocasionando maiores chances de atrito entre os funcionários, como é o caso da UTI e do BC. Sendo assim, os setores em questão tornam-se lugares causadores de estresse ocupacional.

Com essa abordagem, nota-se a necessidade da criação de momentos agradáveis ou confraternizações entre a equipe de enfermagem, a fim de desenvolver atividades em grupo na perspectiva de amenizar a sobrecarga e a pressão gerada dentro de um setor fechado, bem como o acompanhamento psicológico de um profissional capacitado.

\section{0 estresse do enfermeiro no gerenciamento/administração do ambiente fechado}

0 gerenciamento do ambiente fechado é evidenciado como um aspecto motivador de estresse ao profissional enfermeiro, sendo confirmado pela excessiva responsabilidade atribuída à função e pelas dificuldades de implantação de novos métodos de trabalho, devido a uma estrutura mais conservadora.

[...] Na parte administrativa eu era responsável pelos funcionários, férias, planilhas. É muita cobrança. (Orquídea)

[...] Hospital antigo, com uma estrutura administrativa antiga [...] às vezes é muito difícil mudar alguma coisa, convencer eles que as coisas mudaram, melhoram e que tem que serem melhoradas. (Rosa)

[...] Administrativa é a mais estressante, pois tu mexes com escalas então tu acabas envolvendo outros turnos, e tudo tem que ser conversado e nem sempre agrada todo mundo. (Tulipa)

Observa-se nos depoimentos, que a função de gerenciamento do enfermeiro é exaustiva e determinante de estresse ocupacional devido à sobrecarga de atividades técnicas e burocráticas, como responsabilidade sobre a equipe técnica, organização 


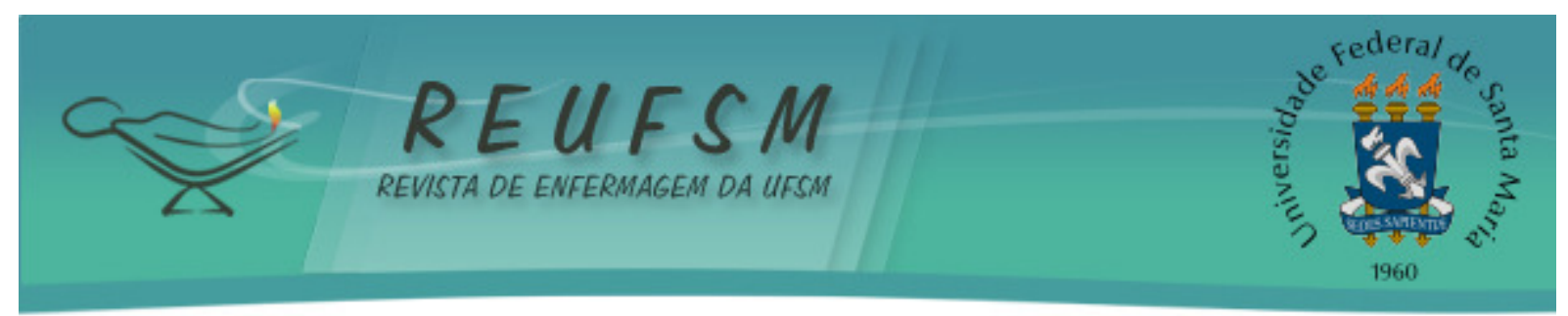

funcional da unidade, elaboração de escalas de trabalho, férias e planilhas para promover a organização do setor. Além disso, uma administração antiga pode dificultar a implantação de novos métodos ou técnicas de trabalho, devido a uma estrutura mais conservadora. Dessa forma, a função de gerenciamento exercida pelo enfermeiro dentro das instituições hospitalares necessita de habilidades e conhecimentos específicos. ${ }^{20}$

Convém ressaltar que as atividades de enfermagem englobam tanto a ação de cuidar quanto a de administrar. No entanto, esta última não é realizada por todas as categorias da enfermagem, e sim pelo enfermeiro, cujo papel é organizar, controlar e favorecer as práticas de cuidar. ${ }^{21}$

Nesse contexto, o acúmulo de funções, as atividades burocráticas e a limitação do tempo para realizar as tarefas são fatores que geram conflitos e esgotamento nos enfermeiros. ${ }^{22} 0$ desenvolvimento de atividades burocráticas apresenta-se como fator estressante ao enfermeiro, por ocupar grande parte de seu tempo, pois este também tem que executar a assistência diferencial ao paciente, já que se trata de um setor fechado. ${ }^{23}$

Um enfermeiro deve ser capaz de mobilizar conhecimentos, informações e atitudes para exercer com capacidade de julgamento, em situações reais e concretas, podendo estas ser individuais ou com sua equipe de trabalho. Dessa maneira, o profissional se sente exausto ao final de seu turno, com a sensação de não ter cumprido suas funções, tornando o trabalho uma fonte inesgotável de paradoxos. ${ }^{24}$

Percebe-se, então, que o gerenciamento ocasiona uma sobrecarga de tarefas para o enfermeiro, tanto administrativas como assistenciais, pois ele é responsável pelo funcionamento do setor, pela organização e pelo andamento do trabalho da equipe, bem como pela conduta administrativa.

\section{CONSIDERAÇÕES FINAIS}

Este estudo permitiu identificar a necessidade dos setores fechados como a UTI e $B C$ de serem constantemente atualizados e modernizados com equipamentos e infraestrutura. Esse empreendimento possibilita aos trabalhadores do serviço a realização de suas atividades de maneira satisfatória e adequada, melhorando a qualidade no atendimento e a assistência aos pacientes.

Assim, verificou-se também que os problemas de relacionamento entre a equipe de enfermagem e equipe multidisciplinar são um fator determinante de estresse. $E$, nesse sentido, a comunicação torna-se uma ferramenta importante para possibilitar esse relacionamento e permitir a partilha de opiniões e expressões. Faz-se necessário a criação de momentos de confraternização multiprofissional, a fim de desenvolver um convívio agradável, amenizar a sobrecarga gerada dentro de um setor fechado e garantir a saúde individual e profissional.

Em relação ao gerenciamento/administração do serviço de enfermagem, este deve ser desenvolvido com a finalidade de colocar em ação o conhecimento teórico e prático, analisar as situações desenvolvidas e resolver os problemas encontrados de acordo com a conduta da instituição. Como foi possível observar, o enfermeiro é um profissional que desenvolve atividades tanto administrativas quanto assistenciais, o que pode ser um agravante ao estresse ocupacional, visto que dificulta a realização de um atendimento completo e integral, gerando frustração e insegurança no trabalho desempenhado. Salienta-se assim a importância de um profissional enfermeiro que desempenhe unicamente o serviço administrativo no setor fechado, permitindo que os demais profissionais de enfermagem realizem de forma produtiva e com maior qualidade o serviço assistencial ao cliente. 


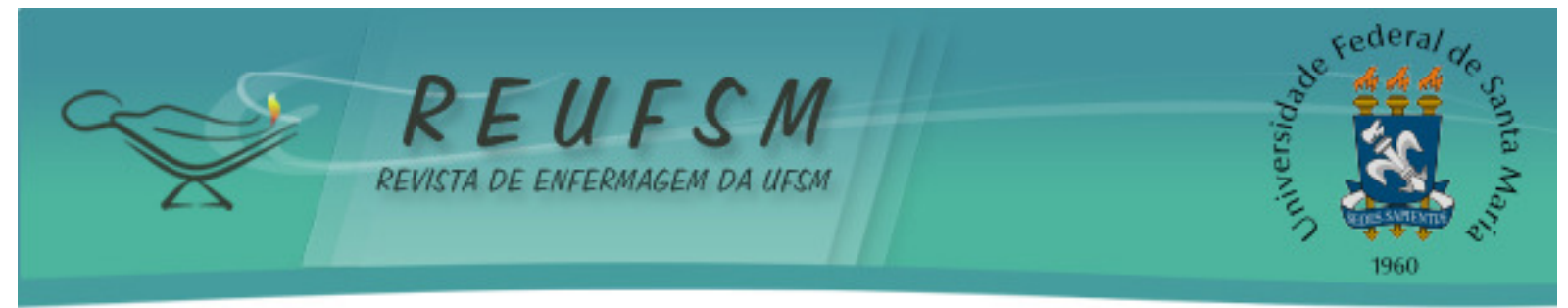

\section{REFERÊNCIAS}

1. Benke MRP, Carvalho E. Estresse $X$ qualidade de vida nas organizações: um estudo teórico. Rev Objetiva [Internet]. 2008 [acesso em 2013 jun 20]; 8(7):1-10 Disponível em: http://www.faculdadeobjetivo.com.br/arquivos/Estresse.pdf.

2. Kaplan IH, Sadock JB. Manual de psiquiatria clínica. $2^{\mathrm{a}}$ ed. Rio de Janeiro: Artmed; 2008.

3. Pafaro RC, De Martino MMF. Estudo de estresse do enfermeiro com dupla jornada de trabalho em um hospital de oncologia pediátrica de Campinas. Rev Esc Enferm USP. 2004; 38(2): 152-60.

4. Peduzzi M, Anselmi ML. Processo do trabalho de enfermagem: a cisão entre o planejamento e execução do cuidado. Rev Bras Enferm. 2002; 55(4):392-8.

5. Barbosa KKS, Vieira KFL, Alves ERP, Virgínio NA. Sintomas depressivos e ideação suicida em enfermeiros e médicos da assistência hospitalar. Rev Enferm UFSM [Internet]. 2012 set/dez [acesso em 2012 dez 10];2(3):515-22. Disponível em: http://cascavel.ufsm.br/revistas/ojs-2.2.2/index.php/reufsm/article/view/5910/pdf.

6. Pereira CA, Miranda LCS, Passos JP. 0 estresse ocupacional da equipe de enfermagem no setor fechado. Rev Pesqui Cuid Fundam [Internet]. 2009 set/dez [acesso em 2011 nov 15]; 1(2):196-202. Disponível em: dialnet.unirioja.es/descarga/articulo/3660786.pdf.

7. Souza RMN. O trabalho nos centros cirúrgicos e as funções psicofisiológicas dos trabalhadores de enfermagem [dissertação]. Rio de Janeiro: Universidade Federal do Rio de Janeiro; 2009. 114 p.

8. Santos NCM. Centro cirúrgico e os cuidados de enfermagem. $6^{\mathrm{a}}$ ed. São Paulo: Látria; 2010.

9. Minayo MCS. O desafio do conhecimento: pesquisa qualitativa em saúde. $10^{a}$ ed. São Paulo: Hucitec; 2007.

10. Dalarosa MG, Lautert L. Acidente com material biológico: risco para trabalhadores de enfermagem em um hospital de Porto Alegre. Rev Gaúch Enferm. 2009;30(1):19-26.

11. Camelo SHH, Angerami ELS. Sintomas de estresse nos trabalhadores atuantes em cinco núcleos de saúde da família. Rev Latinoam Enferm. 2004; 12(1):14-21.

12. Silva AC, Aguiar BGC. O enfermeiro na Central de Material e Esterilização: uma visão das unidades consumidoras. Rev Enferm UERJ. 2008; 16(3):377-81.

13. Lima CD, Lopes MA, Gonçalves VMS. O enfermeiro no planejamento do espaço físico hospitalar. Rev Enferm Integr (Ipatinga). 2010; 3(2):484-93.

14. Jeong DYJ, Kurcgant P. Fatores de insatisfação no trabalho segundo a percepção de enfermeiros de um hospital universitário. Rev Gaúch Enferm. 2010; 31(4):655-61.

15. Barboza MCN. A relação do absenteísmo com o ambiente de trabalho e sua interferência no cuidado de enfermagem [dissertação]. Rio Grande (RS): Universidade Federal do Rio Grande; 2010. 129 p.

16. Coronetti A, Nascimento ERP, Barra DCC, Martins JJ. O estresse da equipe de enfermagem na unidade de terapia intensiva: o enfermeiro como mediador. Arq Catarin Med [Internet]. 2006 [acesso em 2011 set 5]; 35(4):36-43. Disponível em: www.acm.org.br/acm/revista/pdf/artigos/394.pdf. 


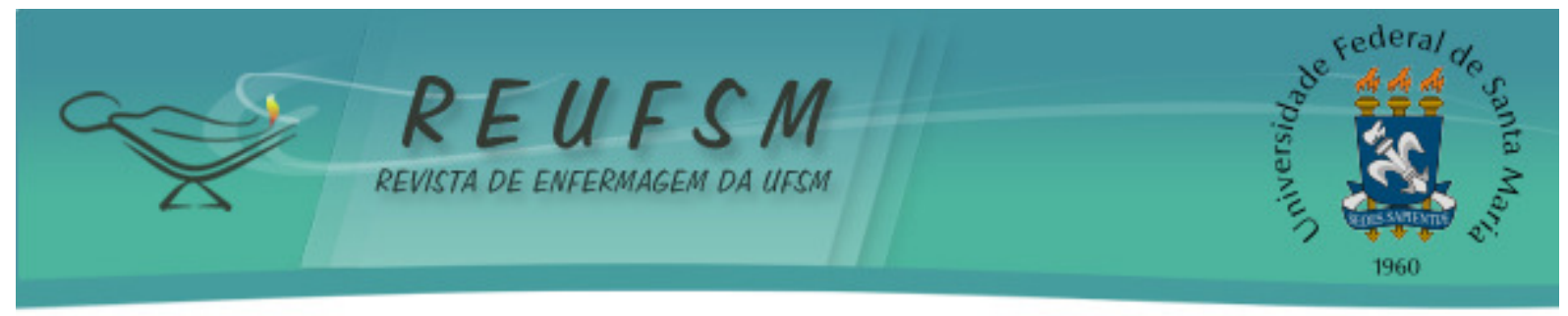

17. Tamayo MR, Tróccoli BT. Construção e validação fatorial da Escala de Caracterização de Burnout (ECB). Psicol Estud [Internet]. 2009 set/dez [acesso em 2011 nov 16];14(3):21321. Disponível em: http://www.scielo.br/pdf/epsic/v14n3/a05v14n3.pdf.

18. Dalmolin GL, Lunardi Filho WD, Lunardi VL. O sofrimento moral dos profissionais de enfermagem no exercício da profissão. Rev Enferm UERJ. 2009;17(1):35-40.

19. Wagner LR, Thofehrn MB, Amestoy SC, Porto AR, Arrieira ICO. Relações interpessoais no trabalho: percepção de técnicos e auxiliares de enfermagem. Cogitare Enferm [Internet]. 2009 jan/mar [acesso em 2011 nov 23];14(1):107-13. Disponível em: http: //ojs.c3sl.ufpr.br/ojs2/index.php/cogitare/article/view/14123/9494.

20. Neves MJAO, Branquinho NCSS, Paranaguá TTB, Barbosa MA, Siqueira KM. Influência do trabalho noturno na qualidade de vida do enfermeiro. Rev Enferm UFRJ. 2010; 18(1):42-7.

21. Backes DS, Backes SM, Sousa FGM, Erdmann AL. O papel do enfermeiro no contexto hospitalar: a visão de profissionais de saúde. Ciênc Cuid Saúde [Internet]. 2008 jul/set [acesso em 2011 nov 12]; 7(3):319-26. Disponível em: http://periodicos.uem.br/ojs/index.php/CiencCuidSaude/article/view/6490/3857.

22. Menzani G, Bianchi ERF. Stress dos enfermeiros de pronto socorro dos hospitais brasileiros. Rev Eletrônica Enferm [Internet]. 2006 [acesso em 2011 dez 13];11(2):327-33. Disponível em: www.fen.ufg.br/fen_revista/v11/n2/pdf/v11n2a13.pdf.

23. Lautert AL. A sobrecarga de trabalho na percepção de enfermeiras que trabalham em hospital. Rev Gauch Enferm. 1999; 20(2): 50-64.

24. Christovam BP, Sanches VF, Silvino ZR. Processo de trabalho do gerente de enfermagem em unidade hospitalar: uma visão dos enfermeiros. Esc Anna Nery Rev Enferm. 2006;10(2):214-20.

Data de recebimento: $10 / 01 / 2013$

Data de aceite: 15/10/2013

Contato com autor responsável: Michele Cristiene Nachtigall Barboza

Endereço postal: Rua Uruguai 1721. CEP: 96010-630. Pelotas, RS, Brasil.

E-mail: michelenachtigall@yahoo.com.br 